\title{
ESTADO DA ARTE DAS PUBLICAÇÕES DOS DISCENTES DO CURSO DE LICENCIATURA EM QUIIMICA
}

\section{Caian Cremasco Receputi}

Universidade Federal do Espírito Santo

E-mail: caian.receputi@gmail.com

\section{ANDREIA WEISS}

Universidade Federal do Espírito Santo

E-mail: andreiaweiss@yahoo.com.br

\section{MARCOS VOGEL}

Universidade Federal do Espírito Santo

E-mail: marcos.vogel@ufes.br

\section{RESUMO:}

Este artigo tem por objetivo apresentar parte dos resultados referentes ao estudo das publicações realizadas pelos discentes do curso de Licenciatura em Química da UFES em Alegre-ES, no período de 2009 a 2013. Para tanto, foram coletados, categorizados usando referenciais de Estado da Arte e analisados 63 publicações contemplando as áreas de Ensino, Ensino de Química e Química. A análise das informações obtidas teve como base a Análise de Conteúdo e os resultados apontam a influência da formação dos docentes formadores e dos Programas de Iniciação Científica/Docência/Extensão e que embora o curso seja de Licenciatura em Química, a maior parte das publicações foi na área de Química.

\section{PALAVRAS-CHAVE:}

Estado da Arte, Pesquisa em Ensino, Pesquisa em Ensino de Química, Pesquisa em Química.

STATE OF THE ART OF STUDENT PUBLICATIONS OF THE COURSE OF GRADUATION IN CHEMISTRY

\section{ABSTRACT:}

This article aims to present part of the results in the study of publication of the students realized of the Chemistry course of UFES in Alegre-ES, from 2009 to 2013. For this purpose, the 63 papers contemplating the areas of Teaching, Teaching of Chemistry and Chemistry, were collected, categorized by using the State of the Art Reference and analyzed. The analysis of the content was based on the Content Analysis Theory. The results shows the influence of the academic education of the training Professors; of the Scientific Initiation / Teaching / Extension Programs; and the most 


\section{DEE Debates

publications was In the Chemistry Area, although the undergraduation of those authors is in Degree in Chemistry.

\section{KEYWORDS:}

State of the Art, Research in Education, Research in Chemistry Teaching, Research in Chemistry.

\section{INTRODUÇÃO}

A Pesquisa em Ensino de Química é uma área com aproximadamente quarenta anos (SCHNETZLER, 2002). Apesar de ser uma área nova, vem apresentando rápido desenvolvimento no âmbito de produção científica, proveniente de publicações em periódicos nacionais e internacionais, e de encontros nacionais e regionais sobre o Ensino de Química, além do crescimento da pesquisa acadêmica em programas de graduação e pós-graduação (SCHNETZLER E ARAGÃO, 1995).

O curso de Licenciatura em Química do Centro da Universidade Federal do Espírito Santo em Alegre-ES foi criado em 2009 a partir da implantação do Programa de Reestruturação e Expansão das Universidades Federais (REUNI). Os docentes e discentes deste curso vêm apresentando uma significativa participação em pesquisas e publicações nas áreas de Ensino, Ensino de Química e Química, englobando diversos eventos locais, regionais e nacionais.

Diante disto, espera-se que estas pesquisas contribuam para a produção de novos conhecimentos, tornando-se de grande importância à produção de pesquisas de levantamento e análise bibliográficas do conhecimento sobre um determinado tema, comumente denominadas de "Estado da Arte", pois compreende-se que tal produção merece ser catalogada, estudada e divulgada de forma ampla e adequada, buscando-se estabelecer as principais tendências destas pesquisas e de suas contribuições para o Ensino de Química. 


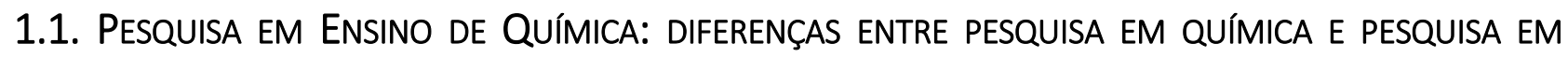 ENSINO}

A área do Ensino de Química situa-se na fronteira entre a área da Educação e a área da Química sendo, atualmente, caracterizada como uma área da Química (CHASSOT, 1995). Porém, apresenta diferenças expressivas da Pesquisa em Química, assim como, diferenças razoáveis da Pesquisa em Ensino.

Enquanto o objetivo da Pesquisa em Química centra-se no estudo das interações de átomos e moléculas, com a dinâmica e mecanismos de transformações químicas, com o estudo das substâncias e da matéria, a Pesquisa em Ensino de Química centra-se nos processos de ensino e aprendizagem do conhecimento químico, na interação entre pessoas e com a dinâmica do conhecimento nas aulas de Química, levando-se em conta as inúmeras variáveis que determinam o contexto social, histórico, econômico e político do processo educativo (SCHNETZLER; ARAGÃO, 1995).

Essas duas áreas também se diferenciam quanto ao método empregado nas pesquisas. De um lado temos, em grande parte da Química, estudos pautados em pesquisas marcadamente quantitativas e positivistas ${ }^{1}$, próprios das Ciências Naturais (CHASSOT, 1995). Do outro lado temos a pesquisa de Ensino de Química que recorre ao método desenvolvido pelos cientistas das Ciências Humanas e Sociais (MILARÉ, 2013).

\footnotetext{
${ }^{1}$ O Positivismo (ou empirismo lógico) é uma corrente filosófica que, teve como um dos seus principais formuladores Auguste Comte (1798 - 1857). Este movimento teve como objetivo justificar e legitimar o conhecimento científico, estabelecendo fundamentos lógicos de como seria uma Ciência ideal, pautada na racionalidade, na objetividade, na verificação empírica, na indução, para assim, atingir verdades absolutas. Para isto estruturou um critério ideal de como o cientista e a comunidade científica deveria agir e pensar. Este movimento foi acatado, principalmente, pelas Ciências (ALVES-MAZZOTTI, GEWANDSZNAJDER, 2002).
} 
Sendo que a Pesquisa em Ensino de Química não pode ser considerada uma aplicação da Pesquisa em Ensino, pois atualmente o seu campo de estudo está pautado na área da Didática das Ciências (SCHNETZLER; ARAGÃO, 1995). Esta, também não apresenta um papel meramente prático, de aplicação dos conhecimentos da Didática das Ciências visto que as Ciências apresentam história, filosofia, e epistemologias próprias, constituindo-se assim em um campo específico de estudo e conhecimento (CACHAPUZ et al., 2001).

Portanto, a identidade da área da Pesquisa em Ensino de Química se apresenta na especificidade do conhecimento químico e na transformação do conhecimento científico proveniente da Química para o conhecimento escolar, diferenciando-a desta forma, das outras áreas do Ensino de Ciências ou da Educação.

\section{METODOLOGIA}

Esta pesquisa apresenta caráter qualitativo, bibliográfico e documental, característico das pesquisas desenvolvidas no âmbito do Estado da Arte (FERREIRA, 2002). Foi necessário debruçar-se em três etapas: i) seleção e recuperação dos documentos; ii) classificação dos documentos e; iii) análise dos dados.

A primeira etapa objetivou o levantamento das publicações, sendo necessário mapear os nomes dos discentes para, posteriormente, mapear as publicações através do Currículo Lattes.

Após a seleção e recuperação das publicações, passou-se para a segunda etapa que constituiu na classificação dos documentos. Após realizar uma leitura flutuante e pesquisar na literatura formas e modelos de classificação e categorização dos documentos optou-se por classificá-las com base nos descritores de Fracalanza (1992), Fernandes (2009) e Milaré (2013), criando, retirando ou modificando alguns 
dos descritores até que a ficha de classificação estivesse mais específica para a investigação desenvolvida.

Dessa etapa resultou sete descritores: i) primeiro autor; ii) demais autores; iii) orientadores; iv) turma/ano de ingresso; v) natureza de publicação; vi) ano de publicação; vii) área de pesquisa.

$\mathrm{Na}$ terceira etapa analisou-se os dados, realizando concomitantemente uma Análise de Conteúdo e uma Análise Documental das publicações levantadas, ambas inspiradas na abordagem de Bardin (1977).

\section{RESULTADOS E DISCUSSÃO}

Nesta etapa apresenta-se a análise e discussão dos dados obtidos das 63 publicações, através da coleta, leitura e classificação, embasada na Análise de Conteúdo proposta por Bardin (1977).

\subsection{QUANTO AOS DISCENTES}

Até o ano de 2014 no curso de Licenciatura em Química encontravam-se 166 discentes ativos e 11 graduados, somando-se assim, o total de 177 discentes e exdiscentes, que daqui por diante serão agrupados para simplificar a análise.

Na Tabela 1, é apresentada a distribuição dos discentes e ex-discentes por ano de ingresso (Turma de Ingresso) e a respectiva porcentagem. Para facilitar a análise e discussão sobre os dados obtidos codificou-se as turmas/ano de ingresso com uma respectiva letra, resultando assim na seguinte ordenação: A: 2009; B: 2010; C: 2011; D: 2012; E: 2013. 
Tabela 1: Distribuição de discentes por turma/Ano. Fonte: Elaborado pelo pesquisador a partir da consulta dos dados fornecidos pelo Coordenador do Curso.

\begin{tabular}{|c|c|c|}
\hline $\begin{array}{c}\text { Turma } \\
\text { Ano / Ingresso }\end{array}$ & Número de Discentes & Porcentagem \\
\hline A -2009 & 22 & 13 \\
\hline B -2010 & 27 & 15 \\
\hline C -2011 & 59 & 33 \\
\hline D -2012 & 48 & 27 \\
\hline E -2013 & 21 & 12 \\
\hline Total & 177 & 100 \\
\hline
\end{tabular}

Nas turmas A e B ofertou-se, em cada ano, 40 vagas, sendo que a média de alunos ativos foi de 24,5 aluno/ano. A partir da turma C, a oferta passou de 40 para 70 vagas, aumentando-se em 75\% o número de vagas disponíveis. Para estas, aumentou-se também a média de alunos, que nas turmas $C$ a $E$ foi de 42,7 aluno/ano. No total, tem-se uma média (dos cinco anos) de 35,4 aluno/ano.

Das cinco turmas, a que possui maior representatividade é a turma C, abrangendo 33\% de todos os discentes, sendo que as turmas C e D juntas abarcam 60\%, mostrando assim, certa irregularidade na distribuição destes discentes. Podendo-se perceber que a quantidade de discentes cresceu da turma A até a turma C e que após esta houve um significativo decrescimento, até que na turma $\mathrm{E}$ tem-se a menor quantidade de discentes de todo o grupo.

Cabe aqui ressaltar que na Portaria Normativa № 728 de 19 de Dezembro de 2013 (BRASIL, 2013) consta que a oferta do número de vagas para o Curso de Licenciatura em Química da UFES em Alegre-ES é de 45, e não de 70 vagas. Como veremos adiante este é um aumento significativo na possível quantidade de alunos e, que sem um estudo adequado juntamente com uma infraestrutura para que isso ocorra, pode ocasionar prejuízo tanto para os discentes quanto para os docentes. 


\subsection{PRIMEIRO AUTOR}

Na Figura 1, é apresentada a distribuição das categorias Primeiro Autor e Demais Autores das 63 publicações analisadas. Destas, somente 51 tiveram como primeira autoria os discentes do curso de Licenciatura em Química. Das 12 publicações restantes, 05 delas contaram como primeira autoria os docentes do curso de Licenciatura em Química e as outras 07 publicações contaram como primeira autoria, discentes e docentes de outros cursos da UFES em Alegre-ES.

Figura 1: Distribuição das publicações quanto à categoria Primeiro Autor. Fonte: Construção dos autores.

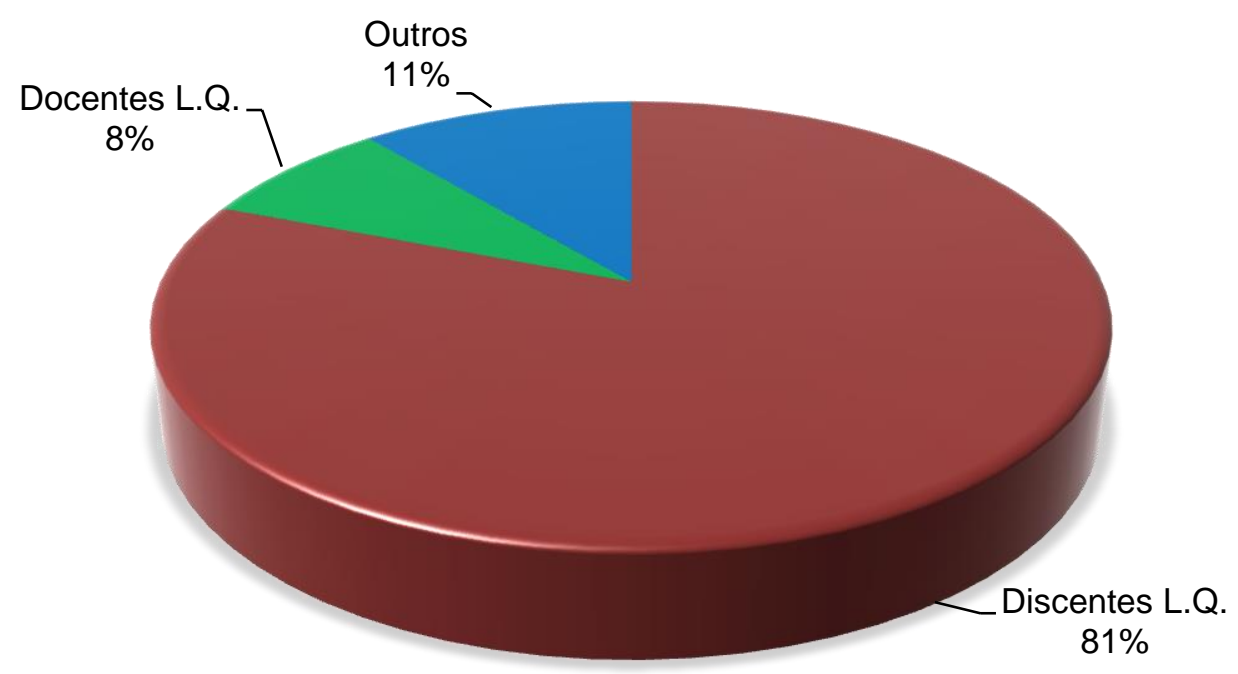

Apesar do grupo dos discentes do curso de Licenciatura em Química ter a maior representatividade nesta categoria não há necessariamente o envolvimento de muitos discentes. Pois das 51 publicações analisadas identificou-se, somente, 25 discentes (diferentes), ou seja, somente $14 \%$ de todos os discentes do curso de Licenciatura em Química efetuaram, como primeiro autor, ao menos uma publicação.

Este fator se agrava ao observarmos (Figura 2) a que turma esses discentes/Primeiro Autor pertencem. 
Figura 2: Distribuição dos discentes Primeiro Autor quanto à Turma de Ingresso. Fonte:

Construção dos autores.

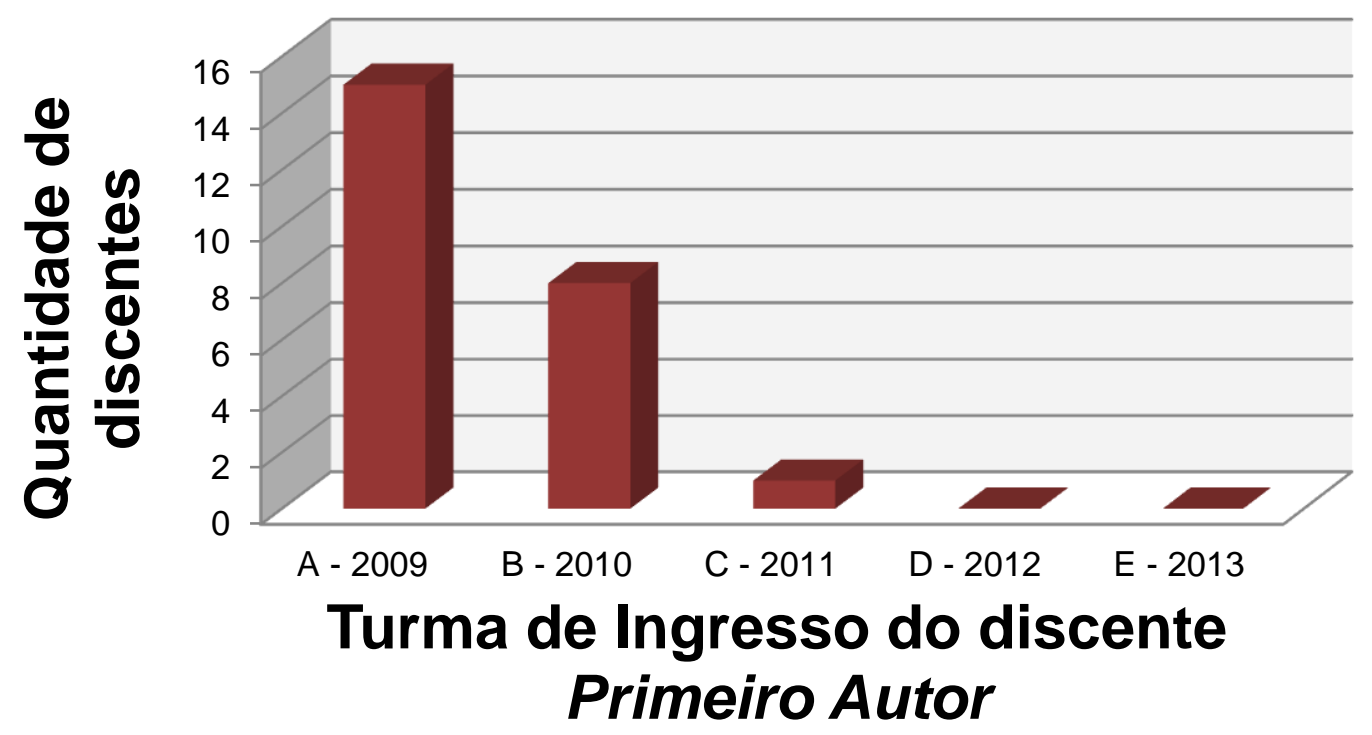

Pode-se observar que do total de discentes/Primeiro Autor, 15 pertencem à turma A, ou seja, 60\% dos primeiros autores ingressaram no curso de Licenciatura em Química no ano de 2009. Porém, como vimos anteriormente (Tabela 1) a parcela mais representativa na quantidade de discentes é a da turma C, a qual apresenta somente 01 e, posteriormente, a turma D, a qual não contempla nenhum discente/Primeiro Autor.

A segunda turma com maior representatividade de discentes/Primeiro Autor é a turma B, contemplando 08 dos 25 discentes, ou seja, 32\%, podendo-se observar uma acentuada redução de discentes/Primeiro Autor a cada Ano/Turma de Ingresso.

\subsection{Demais Autores}

Das 63 publicações analisadas, 38 contemplam a categoria Demais Autores. Indicando que os discentes do curso de Licenciatura em Química optam por realizar as publicações em parceria com outros discentes do próprio curso. Lembrando-se que aqui se contabilizou somente 38 publicações, pois os docentes do curso de 
Licenciatura em Química entram na categoria Orientador(es) e, que os discentes e docentes de outros cursos são omitidos.

Das 25 publicações restantes, 04 contemplaram somente um dos discentes do curso de Licenciatura em Química, sendo essas realizadas através de parcerias com docentes ou pesquisadores de outros setores ou localidades. As outras 21 publicações abrangem pelo menos um dos docentes do curso de Licenciatura em Química. Em algumas dessas 25 publicações participaram outros discentes, docentes e pesquisadores.

Das 38 publicações, 29 contemplaram somente um discente/Demais Autores, 08 contemplaram dois discentes/Demais Autores e, 01 publicação contemplou 03 discentes/Demais Autores.

Logo, contabilizando as repetições de discentes em diferentes publicações chegou-se a um total de 48 menções, mas identificaram-se somente 24 discentes (diferentes) como Demais Autores, mostrando uma constância quanto à quantidade de discentes que participaram das publicações, pois como foi apresentado anteriormente na categoria Primeiro Autor, há participação de 25 discentes.

Os discentes/Demais Autores foram distribuídos por Ano/Turma de Ingresso, assim como as menções (repetições), como mostra a Figura 3. 
Figura 3: Distribuição dos Demais Autores quanto à Turma de Ingresso. Fonte: Construção Dos Autores.

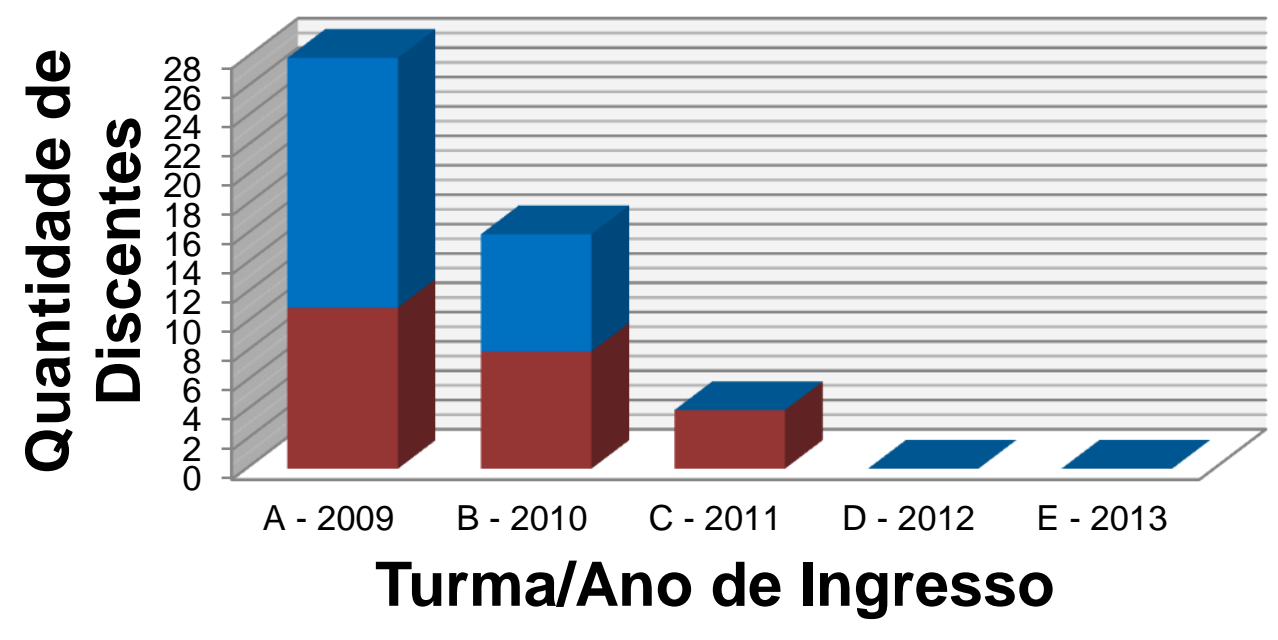

- Total de Menções

- Discentes Demais Autores

Dos 24 discentes/Demais Autores, 11 pertencem à turma A, somando-se assim, 46\%, apresentando uma queda em relação aos discentes Primeiro Autor da mesma turma (60\%). Ainda, a turma A foi a que apresentou a maior repetição de Demais Autores nas publicações, somando 17 repetições, totalizando-se em 28 participações quanto à publicação.

A Turma B contemplou 08 discentes, o que corresponde 33\%. Ao comparar-se com os discentes/Primeiro Autor da mesma turma, observa-se uma constância, pois passa de 32\% (Primeiro Autor) para 33\% (Demais Autores). Ainda, nesta turma observa-se 08 repetições dos discentes/Demais Autores, totalizando em 16 participações quanto à publicação.

Já na Turma C que contemplou 04 discentes/Demais Autores (17\%), observa-se um aumento significativo comparado com o discente/Primeiro Autor da mesma turma, que foi de 4\%. Ainda, observa-se que nestes não houve repetição quanto à participação nas publicações. 
Novamente, nas turmas D e E não houve participação de discentes nas publicações, observando-se assim, uma acentuada redução quanto à quantidade de discentes Demais Autores por Ano/Turma de Ingresso.

A forma em que os dados foram apresentados aparenta ter a participação de 49 discentes (25 discentes/Primeiro Autor + 24 discentes/Demais Autores), entretanto vários dos discentes incluídos na categoria Primeiro Autor também fizeram parte da categoria Demais Autores. Assim, dos 177 discentes, identificou-se a participação de somente 33 discentes, o que representa 19\% do total.

Através da análise das publicações e dos Currículos Lattes dos discentes, observou-se que a maioria das publicações foram desenvolvidas no âmbito de Projetos de Iniciação Científica, Iniciação à Docência ou de Extensão ${ }^{2}$. Logo, a maioria dos discentes das turmas A e B participaram de pelo menos um desses programas ${ }^{3}$, contrastando com a baixíssima participação dos discentes das demais turmas.

De acordo com a legislação brasileira, as Universidades devem ter como eixo balizador a indissociabilidade entre Ensino, Pesquisa e Extensão. Essa afirmativa se pauta no artigo 207 da Constituição Brasileira de 1988 (BRASIL, 2012). Portanto, essas funções básicas devem ser trabalhadas proporcional e concomitantemente, caso contrário, violam o preceito legal (MOITA; ANDRADE, 2009).

Percebe-se que para as turmas A e B este princípio é respeitado, no entanto para as demais turmas, há um desvio desta indissociabilidade. Há incerteza quanto à

\footnotetext{
${ }^{2}$ Das 63 publicações, em 51 há menção, no corpo de texto ou nos agradecimentos, a Projetos de Iniciação Científica, Iniciação à Docência e/ou Projetos de Extensão.

${ }^{3}$ Dos 25 discentes/Primeiro Autor, 23 deles participaram de pelo menos um projeto supracitado. Dos 24 discentes/Demais Autores, 20 deles participavam de pelo menos um projeto.
} 
necessidade de expansão da oferta de vagas para o curso de Licenciatura em Química da UFES em Alegre-ES, como mencionado anteriormente.

\subsection{ORIENTADORES}

No Relatório de Avaliação do Curso do ano de 2012 constava que o curso Licenciatura em Química contavam com 22 docentes vinculados. A partir da análise do Currículo Lattes, observou-se que do total, somente 12 possuíam formação nas áreas de Ensino ou Química, sendo que a formação dos demais contemplam a área de Matemática, Física, Farmácia ou áreas afins.

Considera-se aqui, que os docentes que contemplam a categoria Orientado(res) são os que possuem formação acadêmica nas áreas de Ensino e/ou Química resultando em somente 12 docentes/Orientado(res). Embora a publicação de um discente englobe a área de Farmácia, entende-se que este é um desvio de padrão, omitindo-se assim, o docente.

A análise das 63 publicações indicou que dos 12 docentes, 09 participaram de ao menos uma publicação. Na tabela 2, apresenta-se a formação acadêmica dos docentes/Orientado(res), no que consta o Currículo Lattes dos mesmos. 
Tabela 2: Formação acadêmica dos docentes/Orientado(res). Fonte: Elaborado pelo pesquisador a partir da consulta do Currículo Lattes de cada docente.

\begin{tabular}{|c|c|c|c|}
\hline \multirow{2}{*}{ Orientador } & \multicolumn{3}{|c|}{ Formação Acadêmica } \\
\cline { 2 - 4 } & Graduação & Mestrado & Doutorado \\
\hline A. V. C. & $\begin{array}{c}\text { Química (Bacharelado } \\
\text { e Licenciatura) }\end{array}$ & Agroquímica & Química \\
\hline A. W. & Pedagogia & Educação & Educação \\
\hline D.P. & Química & Química & Química \\
\hline G. A. O. B. & Química & Química & Química \\
\hline H. S. M. & Farmácia e Química & Química & Química \\
\hline L.P. R.P. & Química & Química & Química \\
\hline M. V. & Química & Ensino de Ciências & Agroquímica \\
\hline P. F.P. & Química & Agroquímica & Bioquímica Agrícola \\
\hline V. T. Q. & Química & Agroquímica & \\
\hline
\end{tabular}

Para auxiliar no processo de análise, se classificou como área de Química as áreas de Agroquímica, Farmácia e Bioquímica Agrícola. Classificou-se também a área da Educação, a qual abrange as áreas de Pedagogia e Ensino de Ciências.

Pode-se observar que dos 09 docentes/Orientador(es), 07 possuem graduação, mestrado e doutorado na área de Química, 01 possui graduação, mestrado e doutorado na área de Educação e, 01 possui graduação em Química e mestrado em Educação ${ }^{4}$.

Há, portanto, hegemonia na formação docente na área de Química sobre a área de Educação. Todavia, no Projeto Pedagógico do Curso de Licenciatura em Química consta que das 46 disciplinas obrigatórias, 19 são da área de Educação e 20

\footnotetext{
${ }^{4}$ Dos demais possíveis orientadores, um (A. S. A.) possui graduação, mestrado e doutorado na área de Química, o segundo (D. R.) possui graduação em Licenciatura em Química, mestrado e doutorado na área de Química e, o terceiro (L. A. P.) possui graduação e mestrado na área de Química.
} 
são da área de Química, indicando-se assim, uma carência de docentes formados na área da Educação.

Um dos reflexos desta carência pode ser percebido ao desvelar-se a que área de conhecimento pertence às publicações em que os discentes estão envolvidos, que como pode ser observado na Figura 4, tende a corresponder à área de formação do docente/Orientador.

Figura 4: Número de Publicações e Área de Publicações por Orientador. Fonte: Construção dos autores.
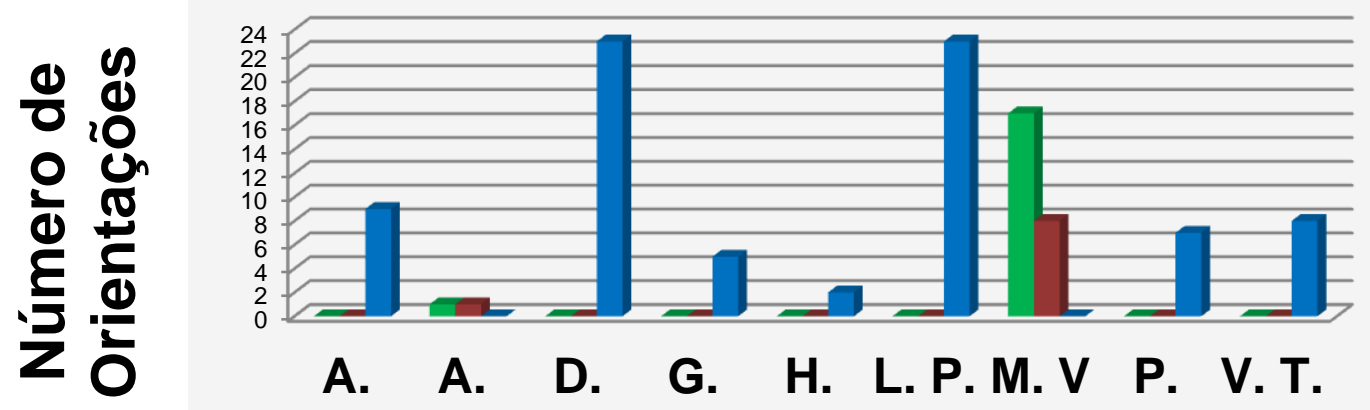
A. A.
D. G.
H. L. P. M. V P. V. T.
V. W.
P.
A. S. M R.
P. F. $Q$
C.
0 .
P.
B.

\section{Orientadores}

Ensino

-Ensino de Química

-Química

Ainda na Figura 4, pode-se observar que os docentes tendem a orientar publicações próximas à sua área de formação. Um fato que corrobora essa afirmação são as publicações que resultam da participação Projetos de Pesquisa e Extensão. Pois das 63 publicações, 51 foram desenvolvidas no âmbito destes projetos, os quais atendem a linha de pesquisa do docente/Orientador, ficando claro que a formação dos docentes influencia na formação dos discentes.

Portanto, os docentes formados em Química orientaram publicações nas áreas de Química e, os formados em Educação, orientaram publicações nas áreas de Educação ou Ensino de Química. 


\subsection{NATUREZA DA PUBLICAÇÃo}

Através da análise das 63 publicações, verificou-se a existência de quatro tipos de publicações. Optou-se por classificá-las a partir de uma mescla na nomenclatura utilizada na Plataforma Lattes (Currículo Lattes) e nos encontros, reuniões, congressos, entre outros.

Os tipos de publicação são: i) artigo completo publicado em periódico (artigo completo); ii) trabalho completo publicado em anais de congresso (trabalho completo); iii) resumo expandido publicado em anais de congresso (resumo expandido) e; iv) resumo publicado em anais de congresso (resumo de trabalho).

Na Figura 5, se apresenta a distribuição das publicações quanto à Natureza de Publicação e o Ano de Publicação.

Figura 5: Distribuição das Publicações quanto à Natureza de Publicação e Ano de Publicação. Fonte: Construção dos autores.

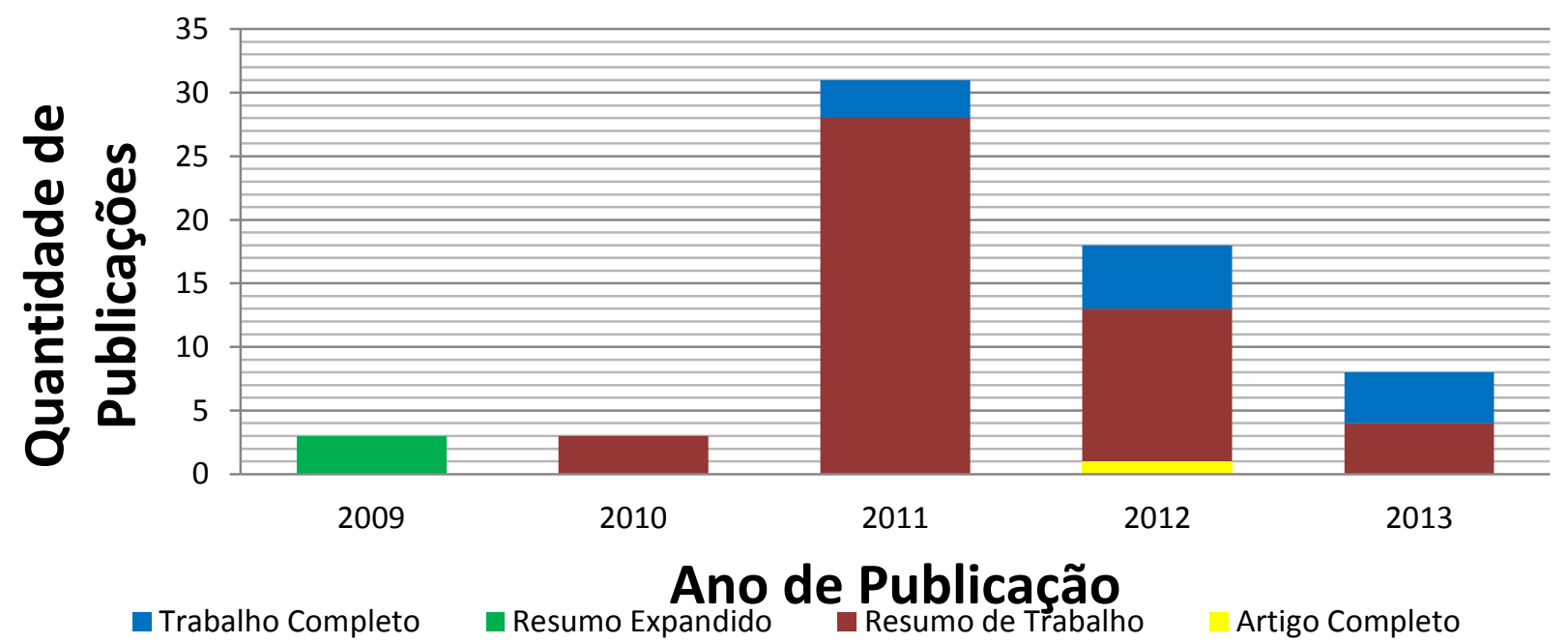

No ano de 2010, verificou-se somente 03 publicações do tipo Resumo de Trabalho. Este é um indício de que, no respectivo ano, os alunos começam a fazer parte de Projetos de Iniciação Científica, Iniciação a Docência ou de Extensão. Notase que em 2011 há um aumento significativo nas publicações, que passa de 03, nos anos de 2009 e 2010, para 31 publicações no ano de 2011. 
Em 2011, percebe-se que das 31 publicações, 28 são do tipo Resumo de Trabalho e 03 são do tipo Trabalho Completo. A partir de 2011 há um contínuo decréscimo, que em 2012 contemplavam 18 publicações e em 2013, 08 publicações. Não foi possível encontrar uma resposta para este decréscimo, já que a cada ano o número de discentes aumenta e deste modo era esperado o aumento do número de publicações.

Das 18 publicações do ano de 2012, 12 são do tipo Resumo de Trabalho, 05 são do tipo Trabalho Completo e 01 é do tipo Artigo Completo. E, finalmente em 2013 temos que das 08 publicações, 04 são do tipo Resumo de Trabalho e 04 dão do tipo Trabalho Completo.

Embora o número de publicações tenha diminuído, houve um significativo aumento no tipo de publicação Trabalho Completo, indicando que o processo de pesquisa e a produção da publicação requerem do discente, além de tempo e apoio, certo nível de maturidade intelectual, técnica e metodológica (SEVERINO, 2008). Ainda, tipos de publicações diferentes requerem graus de maturidade distintos.

Assim, a maior parte das publicações foi do tipo Resumo de Trabalho (47), em seguida temos as publicações do tipo Trabalho Completo (12), logo após as publicações do tipo Resumo Expandido (03), e por último, a publicação do tipo Artigo Completo (01).

\section{6. ÁREA DE PESQUISA}

Na Figura 6, apresenta-se a distribuição das 63 publicações quanto à Área de Pesquisa, no período de 2009 a 2013. Percebe-se que a maior parte das publicações direcionaram-se para a área de Pesquisa em Química, resultando em 37 publicações. Esta quantidade representa mais que o dobro das publicações voltadas para área de 
Pesquisa em Ensino (17 publicações) e mais que o quadruplo das publicações voltadas para área de Pesquisa em Ensino de Química (08 publicações).

Figura 6: Distribuição das Publicações quanto à Área de Pesquisa no período de 2009 a 2013. Fonte: Construção dos autores.

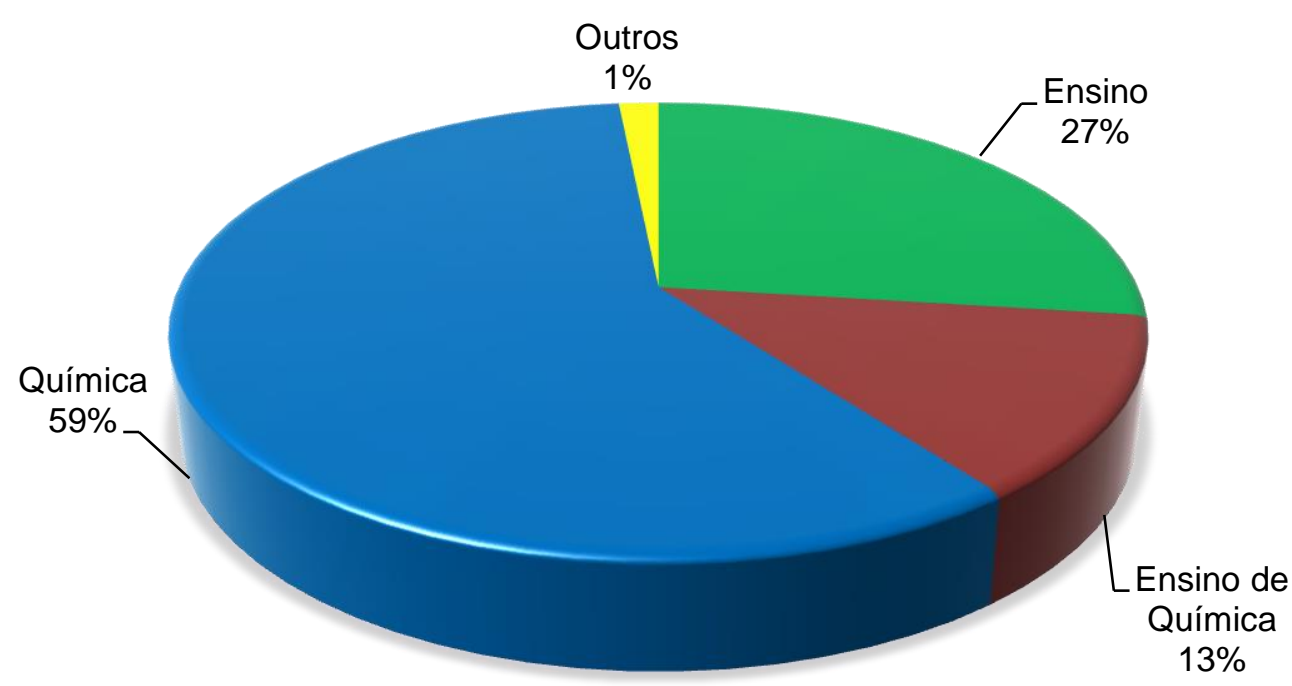

Embora o respectivo curso seja de Licenciatura em Química e com isso era esperado que a maior parte das pesquisas e publicações voltasse para a área de Ensino de Química, observa-se um desvio das mesmas, voltando-se mais para área de Química.

Esse desvio pode ser explicado, em parte, pela formação dos docentes que, como vimos na Tabela 2, apresenta uma hegemonia na área de Química sobre a área de Educação, representando certa influência nas publicações dos discentes, pois como vimos na Figura 5, tende a se aproximar da área de formação do docente.

\section{CONCLUSÃO}

Inicialmente, destaca-se que a partir da criação do curso de Licenciatura em Química da UFES em Alegre-ES ocorreu, progressivamente, a elaboração e implantação de Projetos de Extensão, Iniciação a Pesquisa e Iniciação à Docência. Sendo estes os responsáveis pela maior parte da elaboração das pesquisas e da 
produção das publicações. Confirmando a fundamental importância destes projetos para a formação dos discentes.

Entretanto, constatou-se que no referido tempo apenas uma pequena parcela de discentes que participaram de publicações (19\%), frente ao predomínio de discentes que não participaram. Não foi possível averiguar se estes discentes não participaram dos projetos, tampouco se eles não participaram, em algum momento, de algum processo de pesquisa. Sendo esta uma característica importante a ser estudada, pois como havíamos mencionado a indissociabilidade entre ensino, pesquisa e extensão faz parte do preceito legal que fundamenta as Universidades.

Apesar de constatarmos poucos discentes participantes, observou-se uma quantidade expressiva de publicações, das quais foi possível realizar a coleta de somente 63 publicações. Afirma-se que as pesquisas dos discentes do curso de Licenciatura em Química da UFES em Alegre-ES vêm sendo desenvolvidas com predominância em três áreas de conhecimento, Ensino, Ensino de Química e Química.

Ao contrário do que era esperado, constatou-se que a área de maior representatividade das publicações voltou-se para a Química, esta por sua vez teve maior representatividade que a soma das publicações das áreas de Ensino e Ensino de Química, apesar do respectivo curso ser o de Licenciatura em Química. A segunda maior representatividade das publicações abrange a área de Ensino e, logo após, a área de Ensino de Química. Com isso, conclui-se que a formação dos docentes e os Projetos de Iniciação Científica, Iniciação à Docência ou de Extensão influenciam na formação dos discentes.

Como contribuição para novas investigações, sugerimos um estudo minucioso sobre a influência das publicações realizadas pelos discentes dos cursos de 
Licenciatura em Química em face de sua trajetória formativa e da construção de uma identidade docente.

\section{REFERÊNCIAS}

ALVES-MAZZOTTI, A. J.; GEWANDSZNAJDER, F. O método nas ciências naturais e sociais: pesquisa quantitativa e qualitativa. 2. ed. São Paulo: Pioneira, 2002.

BARDIN, L. Análise de Conteúdo. Lisboa: Edições 70,1977.

BRASIL. Constituição da Republica Federativa do Brasil. 35. ed. Brasília: Câmara dos Deputados, Edições Câmaras, 2012.

CACHAPUZ, A. et al. A emergência da Didática das ciências como campo específico de conhecimento. Revista Portuguesa de Educação, v. 14, n. 1, p. 155-195, 2001.

CHASSOT, A. Para que(m) é útil o Ensino? Canoas: Ed. da Ulbra, 1995.

DURKHEIM, E. Educação e Sociologia. São Paulo: Hedra, 2010.

FERNANDES, R. C. A. Tendências da pesquisa acadêmica sobre o ensino de ciências nas séries iniciais da escolarização. Dissertação de Mestrado. Universidade Estadual de Campinas, Campinas, 2009.

FERREIRA, N. S. A. As pesquisas denominadas "Estado da Arte". Campinas: Revista Educação \& Sociedade, n. 79, p. 257-272, Ago. 2002.

FRACALANZA, H. O que sabemos sobre livros didáticos para o ensino de ciências no Brasil. Tese de Doutorado. Universidade Estadual de Campinas, Campinas, 1992.

MILARÉ, T. A pesquisa em ensino de química na Universidade de São Paulo: estudo das dissertações e teses (2006 a 2009) sob a perspectiva fleckiana. Tese de doutorado. Universidade de São Paulo. São Paulo, 2013. 
MOITA, F. M. G. S. C.; ANDRADE, F. C. B. Ensino-pesquisa-extensão: um exercício de indissociabilidade na pós-graduação. Revista Brasileira de Educação, v. 14, n. 41, p. 269-293, 2009.

SCHNETZLER, R.P; ARAGÃO, R.M. Importância, sentido e contribuições de pesquisas para o ensino de Química. Revista Química Nova na Escola, n. 1, p. 27-31, 1995.

SCHNETZleR, R. P. A Pesquisa em Ensino de Química no Brasil: Conquistas e Perspectivas. Revista Química Nova, v. 25, supl. 1, p. 14-24, 2002.

SEVERINO, A. J. Ensino e pesquisa na docência universitária: caminhos para integração. São Paulo. Cadernos de Pedagogia Universitária. São Paulo: Pró-Reitoria de Graduação, v. 3, 2008.

SEVERINO, A. J. Metodologia do Trabalho Científico. 21. ed. São Paulo: Cortez, 2000.

SOARES, M. Alfabetização no Brasil: O Estado do conhecimento. Brasília: INEP/MEC, 1989.

Recebido em: Março de 2017. Publicado em: Dezembro de 2017. 